\title{
Correlations between SAR arc intensity and solar and geomagnetic activity
}

\author{
V. V. Lobzin, A. V. Pavlov \\ Institute of Terrestrial Magnetism, Ionosphere, and Radio-Wave Propagation, Russian Academy of Sciences (IZMIRAN) \\ Troitsk, Moscow Region, 142092, Russia; Fax: + 7095 3340124; E-mail: lobzin@top.izmiran.troitsk.ru
}

Received: 30 April 1998 / Revised: 2 November 1998 / Accepted: 10 November 1998

\begin{abstract}
We present a study of statistical relationships between SAR arc intensities acquired by the Pacific Northwest Laboratory Photometer Network during 1978-1988 and solar and geomagnetic activity indices Dst, F10.7, and $K p$ by use of the method of multiple regression analysis. We found significant correlations between intensity and all of the indices involved. In the present work we show for the first time that the partial correlation coefficients depend on the time offset, $t$, between the time of SAR arc intensity observations and the onset of the geomagnetic storm recovery phase, with the largest correlations being observed when $8 \mathrm{~h} \leq t \leq 16 \mathrm{~h}$. It is also shown that there are significant differences between partial correlation coefficients calculated for SAR arcs associated with strong $\left(D s t_{\min } \leq-100 \mathrm{nT}\right)$ and weak $\left(D s t_{\min }>-100 \mathrm{nT}\right)$ geomagnetic storms. We observe also that the multiple correlation coefficients for strong storms are much larger than for weak ones. We found that the variations in the electron temperature, $T_{e}$, in the SAR arc region are not mainly produced by variations in the electron density of the ionosphere but are strongly driven by the additional heating of the electron gas due to an interaction of the ring current ions and the plasmaspheric electrons. As a result, variations of $T_{e}$ in the SAR arc region with characteristic time scales from several minutes to several hours are stipulated by time variations of ring current parameters.
\end{abstract}

Key words. Atmospheric composition and structure (airglow and aurora) Ionosphere (ionosphereatmosphere interactions; ionosphere-magnetosphere interactions).

\section{Introduction}

During the recovery phase of large magnetic storms characterized by a geomagnetic index $K p$ of 5 or greater, stable auroral red (SAR) arcs are observed optically on the equatorward edge of the midlatitude ionospheric trough (Rees and Roble, 1975; Kozyra et al., 1997). The characteristic spectral emission at $630 \mathrm{~nm}$ that identifies a SAR arc is associated with the atomic oxygen transition OI $\left({ }^{3} \mathrm{P}_{2}-{ }^{1} \mathrm{D}_{2}\right)$. The centre of the SAR arc emission is usually observed in the region between 350 and $450 \mathrm{~km}$ in altitude. The ring current is a primary energy source for maintenance of SAR arcs (Kozyra et al., 1997). As a result, the observed SAR arc intensity is influenced by a number of factors associated with the energy exchange and transformation in the ring currentplasmasphere-atmosphere system.

Using a small data set of bright SAR arc observations performed during the solar cycle maximum in 1956-1960, Rees and Akasofu (1963) and Roach and Roach (1963) found that there are correlations of the SAR arc intensities with $D s t$ and $K p$. It was also noted that the frequency of SAR arc occurrence is greatest during the solar cycle maximum and this frequency is diminished greatly as the Sun proceeded through the solar cycle minimum (Rees and Roble, 1975; Rees and Akasofu, 1963; Slater and Kleckner, 1989; Kozyra et al., 1997). The main goal of the present study is to find the statistical relationships between SAR arc intensities and solar and geomagnetic activity measured in terms of indices $D s t, F 10.7$, and $K p$, using the data acquired by the Pacific Northwest Laboratory Photometer Network during 1978-1988 (more than $1000 \mathrm{~h}$ of measurements) (Slater and Kleckner, 1989). The statistical study of large data sets can shed some light on mechanisms of energy transfer from the ring current to the plasmasphere and ionosphere and investigate which formulas relating SAR arc intensities with the solar and geomag-

Correspondence to: V. V. Lobzin 
netic indices can produce the best agreement between observed and predicted values of these intensities.

Simultaneous measurements of SAR arc electron densities, $N_{e}$, and temperatures, $T_{e}$, showed that the electron temperature does not depend on the electron density (Fok et al., 1991a, b; Kozyra et al., 1997). In this work we solve the energy balance equation in the ionosphere and plasmasphere along a magnetic field line associated with an SAR arc region and study the relationship between the electron temperature and density in the SAR arc region. This approach allows us to study the processes controlling the SAR arc emission at $630 \mathrm{~nm}$ and explain experimental data.

\section{Theoretical study of relationships between SAR arc intensities and parameters of the neutral atmosphere, ionosphere, and ring current}

The volume emission rate, $V$, and the integral intensity, $I$, of airglow at $630 \mathrm{~nm}$ are given as

$V=A_{630}\left[\mathrm{O}\left({ }^{1} \mathrm{D}\right)\right]$,

$I=\int_{0}^{\infty} V(z) \mathrm{d} z$

where $A_{630}=5.61 \cdot 10^{-3} \mathrm{~s}^{-1}$ is the Einstein coefficient for the atomic oxygen transition $\mathrm{O}\left({ }^{1} \mathrm{D}_{2}\right) \rightarrow \mathrm{O}\left({ }^{3} \mathrm{P}_{2}\right)+h v$ (Bhatia and Kastner, 1995), and $z$ is a height.

The $\mathrm{O}\left({ }^{1} \mathrm{D}\right)$ number density is calculated from the continuity equation taking into account the chemical reactions of formation and loss of $\mathrm{O}\left({ }^{1} \mathrm{D}\right)$, the production of $\mathrm{O}\left({ }^{1} \mathrm{D}\right)$ in the photodissociation reaction of oxygen molecules, the $\mathrm{O}\left({ }^{1} \mathrm{D}\right)$ formation in collision of $\mathrm{O}\left({ }^{3} \mathrm{P}\right)$ with thermal electrons and photoelectrons, and the diffusion of $\mathrm{O}\left({ }^{1} \mathrm{D}\right)$ in the mixture of $\mathrm{N}_{2}, \mathrm{O}_{2}$, and $\mathrm{O}$ (Pavlov, 1997). The inclusion of the $\mathrm{O}\left({ }^{1} \mathrm{D}\right)$ diffusion results in a decrease of $4-6 \%$ in the calculated integral intensity of the Northern Hemisphere and $7-13 \%$ in the calculated integral intensity of the Southern Hemisphere (Pavlov, 1997) and is not taken into account in this study. As a result, the steady-state $\mathrm{O}\left({ }^{1} \mathrm{D}\right)$ number density is given as

$\left[\mathrm{O}\left({ }^{1} \mathrm{D}\right)\right]=P /\left\{A+K_{1}\left[\mathrm{~N}_{2}\right]+K_{2}\left[\mathrm{O}_{2}\right]+K_{3}[\mathrm{O}]\right\}$,

where $P$ is the production rate of $\mathrm{O}\left({ }^{1} \mathrm{D}\right)$, $A=A_{630}+A_{636.4}+A_{639.2}, A_{636.4}=1.82 \cdot 10^{-3} \mathrm{~s}^{-1}$ and $A_{639.2}=8.92 \cdot 10^{-7} \mathrm{~s}^{-1}$ are the Einstein coefficients for the atomic oxygen transitions $\mathrm{O}\left({ }^{1} \mathrm{D}\right) \rightarrow \mathrm{O}\left({ }^{3} \mathrm{P}_{1}\right)+h v$ and $\mathrm{O}\left({ }^{1} \mathrm{D}\right) \rightarrow \mathrm{O}\left({ }^{3} \mathrm{P}_{0}\right)+h v$ (Bhatia and Kastner, 1995), $K_{1}=2.0 \cdot 10^{-11} \exp \left(107.8 T_{\mathrm{n}}^{-1}\right) \mathrm{cm}^{3} \mathrm{~s}^{-1}$ is the rate coefficient for quenching of $\mathrm{O}\left({ }^{1} \mathrm{D}\right)$ by molecular nitrogen (Streit et al., 1976), $K_{2}=2.9 \cdot 10^{-11} \exp \left(67.5 T_{\mathrm{n}}^{-1}\right)$ $\mathrm{cm}^{3} \mathrm{~s}^{-1}$ is the rate coefficient for quenching of $\mathrm{O}\left({ }^{1} \mathrm{D}\right)$ by molecular oxygen (Streit et al., 1976), $K_{3}=$ $2.5 \cdot 10^{-12} \mathrm{~cm}^{3} \mathrm{~s}^{-1}$ is the rate coefficient for quenching of $\mathrm{O}\left({ }^{1} \mathrm{D}\right)$ by atomic oxygen (Sobral et al., 1993).

In the SAR arc region, $\mathrm{O}\left({ }^{1} \mathrm{D}\right)$ are produced mainly by excitation of $\mathrm{O}\left({ }^{3} \mathrm{P}\right)$ by thermal electron impact
(Kozyra et al., 1997). The production rate of $\mathrm{O}\left({ }^{1} \mathrm{D}\right)$ arising from the collisions of thermal electrons with $\mathrm{O}\left({ }^{3} \mathrm{P}\right)$ can be calculated as (Pavlov, 1990, 1996, 1997)

$P=N_{e}[O] f\left(T_{e}\right)$,

where $f\left(T_{e}\right)=\left\{8 \mathrm{k} T_{e}\left(\pi m_{e}\right)^{-1}\right\}^{0.5} \int_{0}^{\infty} \sigma(x) x \exp (-x) \mathrm{d} x$, $x=E\left(\mathrm{k} T_{e}\right)^{-1}, \sigma(E)$ is the cross section for excitation of the $\mathrm{O}\left({ }^{1} \mathrm{D}\right)$ state by electrons, $E$ is the energy of electrons, $\mathrm{k}$ is the Boltzmann constant, and $m_{e}$ denotes the mass of electron.

The $\mathrm{O}\left({ }^{3} \mathrm{P} \rightarrow{ }^{1} \mathrm{D}\right)$ cross section has been measured by Doering (1992) for incident electron impact energies of 4.0 to $30 \mathrm{eV}$. To find an analytical expression for $f\left(T_{e}\right)$ we used the linear interpolation of the measured $\sigma(E)$ between fixed incident energies from the threshold (where $\sigma(E)=0$ ) to $30 \mathrm{eV}$. This assumption leads to the simple approach in calculations of $f\left(T_{e}\right)$ as $f\left(T_{e}\right)=4.73 \cdot 10^{-12} T_{e}^{0.7} \exp \left(-22829 / T_{e}\right)$, where the unit of $T_{e}$ is $\mathrm{K}$ and the unit of $f\left(T_{e}\right)$ is $\mathrm{cm}^{3} \mathrm{~s}^{-1}$. We found that the value of maximum error for this analytical expression for $f\left(T_{e}\right)$ is less than $2 \%$ within the electron temperature range $1400-6000 \mathrm{~K}$ and this accuracy is enough in our studies.

In this case, from Eqs. (1)-(4) it follows that the integral intensity is

$$
\begin{aligned}
I=A_{630} \int_{0}^{\infty} & N_{e} f\left(T_{e}\right)[\mathrm{O}] / \\
& \left\{A+K_{1}\left[\mathrm{~N}_{2}\right]+K_{2}\left[\mathrm{O}_{2}\right]+K_{3}[\mathrm{O}]\right\} \mathrm{d} z .
\end{aligned}
$$

The peak volume emission rate is usually observed close to the F2-peak altitude in the altitude range of 350$450 \mathrm{~km}$ (Rees and Roble, 1975) and the main contribution to the SAR arc intensity occurs near the altitude of this peak volume emission rate. Since the electron density and temperature scale lengths in the altitude directions are much greater than altitude scale lengths of $\mathrm{O}, \mathrm{N}_{2}$, and $\mathrm{O}_{2}$ at the altitudes considered, we can assume that $N_{e}$ and $T_{e}$ are approximately constant in Eq. (5). These assumptions lead to the more simple expression for the integral intensity as

$I=A_{630}\left\langle N_{e}\right\rangle\left\langle f\left(T_{e}\right)\right\rangle J$,

where

$J=\int_{z_{\min }}^{z_{\max }}[\mathrm{O}] /\left\{A+K_{1}\left[\mathrm{~N}_{2}\right]+K_{2}\left[\mathrm{O}_{2}\right]+K_{3}[\mathrm{O}]\right\} \mathrm{d} z$,

$\left\langle N_{e}\right\rangle \approx N_{e}\left(z_{0}\right), \quad\left\langle f\left(T_{e}\right)\right\rangle \approx f\left(T_{e}\left(z_{0}\right)\right), z_{0}$ is a peak volume emission rate altitude, $z_{\min }=200 \mathrm{~km}$ and $z_{\max }=$ $800 \mathrm{~km}$.

The value of the ratio $I / J$ is proportional to $\left\langle N_{e}\right\rangle\left\langle f\left(T_{e}\right)\right\rangle$ and this ratio is expected to be less sensitive to variations of neutral densities than the value of $I$. Nevertheless, the magnitude of the electron density is controlled in part by the neutral atmosphere and the dependence of $\left\langle N_{e}\right\rangle$ on neutral temperature and densities can give an input to relationship between $I / J$ and solar and geomagnetic activity indices $F 10.7$ and $K p$. 
The values of $I$ and $I / J$ depend on the value of $T_{e}$ at the altitudes close to a peak volume emission rate altitude. The dependence of the electron temperature in the SAR arc region on parameters of the ring current, ionosphere, and neutral atmosphere is determined by the energy balance equation for electrons (Pavlov, 1997):

$$
\begin{aligned}
1.5 \mathrm{k} N_{e} \frac{\partial}{\partial t} T_{e}= & B \frac{\partial}{\partial s}\left(B^{-1} \Phi\right)+Q_{p h} \\
& +Q_{r c}-\sum_{i} L_{e i}-\sum_{n} L_{e n},
\end{aligned}
$$

where $B$ is the magnitude of the geomagnetic field, $s$ is a distance measured along the magnetic field line, positive in the direction north to south; $s=0$ corresponds to the point at the geomagnetic equator, $Q_{p h}$ is the heating rate of the electron gas by photoelectrons, $Q_{r c}$ is an additional heating rate of the electron gas due to an interaction of the ring current ions and plasmaspheric electrons during SAR arc events, $L_{e i}$ and $L_{e n}$ are the electron cooling rates due to collisions of electrons with thermal ions and neutrals, $\Phi=\kappa T_{e}^{5 / 2} \partial T_{e} / \partial s$ is an electron heat flux along a magnetic field line, $\kappa$ is the multicomponent electron thermal conductivity coefficient given by Pavlov (1996) $\left(\kappa=7.7 \cdot 10^{5} \mathrm{eV} \mathrm{cm}^{-1} \mathrm{~s}^{-1}\right.$ $\mathrm{K}^{-7 / 2}$ in the fully ionized gas (Spitzer, 1962)).

Several excitation mechanisms have been proposed to account for the heating of the electron gas in the SAR arc region, such as Coulomb collisions between ring current ions and plasmaspheric electrons and ions, Landau damping of ion cyclotron waves, and resonant damping of kinetic Alfven waves (Cole, 1965; Kozyra et al., 1987; Kozyra et al., 1997; Kozyra and Nagy, 1991; Cornwall et al., 1971; Thorne and Horne, 1992, 1997; Erlandson et al., 1993). Up to now, the role of the plasma waves in producing SAR arcs is unclear and the Coulomb mechanism is the most plausible mechanism used to explain not only observed electron temperature enhancements but also the associated SAR arcs (Kozyra et al., 1997).

The electron heating rate due to Coulomb collisions between ring current ions and plasmaspheric electrons is given as (Cole, 1965; Kozyra et al., 1987)

$Q_{r c}=C N_{e} T_{e}^{-1 / 2}$

where

$C=8 \pi e^{4} \ln \Lambda\left(2 \mathrm{k} m_{e}\right)^{-1 / 2} \sum_{j} \int_{0}^{\infty} F\left(x_{j}\right) G\left(x_{j}\right) \mathrm{d} x_{j}$,

$e$ denotes the electron charge, $\ln \Lambda$ is the Coulomb logarithm, $j=\mathrm{H}^{+}, \mathrm{O}^{+}, x_{j}=W_{j} / V_{T_{e}}, W_{j}$ is a velocity of ring current ions, $V_{T_{e}}=\left(2 \mathrm{k} T_{e} / m_{e}\right)^{1 / 2}, F$ is an omnidirectional flux of ring current ions, $G\left(x_{j}\right)=\left[\operatorname{erf}\left(x_{j}\right)-\right.$ $\left.x_{j} \operatorname{erf}^{\prime}\left(x_{j}\right)\right]\left(2 x_{j}^{2}\right)^{-1}$ is the function tabulated by Spitzer (1962). The function $G\left(x_{j}\right)$ maximizes at $x_{j}=1$, when the energy of ring current ions is $E_{j}^{*}=\mathrm{k} T_{e} m_{j} m_{e}^{-1}$, where $m_{j}$ denotes the mass of $j$-th ion, and falls off rapidly on either side of this value. The values of $E_{j}^{*}$ are $1.8 \mathrm{keV}$ and $29.4 \mathrm{keV}$ for $\mathrm{H}^{+}$and $\mathrm{O}^{+}$ions if $T_{e}=1 \mathrm{eV}$. For all cases studied by Kozyra et al. (1987) the value of $F$ for $\mathrm{H}^{+}$ions at $E=1.8 \mathrm{keV}$ is much smaller than the value of $F$ for $\mathrm{O}^{+}$ions at $E=29.4 \mathrm{keV}$, and, therefore, Coulomb collisions between ring current $\mathrm{O}^{+}$ions and plasmaspheric electrons determine the electron heating rate.

To study the energy balance of electrons in the ionosphere and plasmasphere, we consider a geomagnetic force tube $-s_{0}<s<s_{0}$, the ends of which are located at the altitudes $z_{0}=120 \mathrm{~km}$. Let in the force tube regions $-s_{0} \leq s \leq-s_{1}$ (the ionosphere of the Northern Hemisphere), $-s_{1} \leq s \leq s_{1}$ (the plasmasphere), and $s_{1} \leq s \leq s_{0}$ (the ionosphere of the Southern Hemisphere) be specified, where the boundaries $s_{1}$ and $-s_{1}$ correspond to the altitude $z_{1}=1400 \mathrm{~km}$.

SAR arcs are usually observed at night and we can neglect $Q_{p h}$ in comparison with $Q_{r c}$ in Eq. (8). Khazanov et al. (1992) found that characteristic time scale $\tau_{e}$ for electron temperature variations in the plasmasphere at $L=3$ (which is typical for SAR arcs) changes from about $12 \mathrm{~min}$ to an hour as the integral electron heating rate decreases from $10^{11} \mathrm{eV} \mathrm{cm}^{-3} \mathrm{~s}^{-1}$ to $10^{10} \mathrm{~cm}^{-3} \mathrm{~s}^{-1}$. Taking into account that an effect of cooling processes on the temperature of plasmasphere electrons is weak, and assuming that $t \gg \tau_{e}$, we can integrate Eq. (8), with respect to $s$ from magnetic equator to the upper boundary of the northern ionosphere along the field line, and obtain the following relation:

$\Phi\left(-s_{1}\right)=\Phi(s=0)-B\left(-s_{1}\right) \int_{-s_{1}}^{0} B(s)^{-1} Q_{r c}(s) \mathrm{d} s$.

We can assume that $\left|\Phi\left(-s_{1}\right)\right| \gg|\Phi(s=0)|$ due to northsouth symmetry of the ring current and plasmasphere in the region of their interaction and conclude that the value of $\Phi\left(-s_{1}\right)$ is determined by the value of $Q_{r c}(s)$.

To examine the dependence of $T_{e}$ in the ionosphere of the Northern Hemisphere on $N_{e}$ and $\Phi\left(-s_{1}\right)$ we use Eq. (8) and the IRI-90 model electron densities (Bilitza, 1990), $N_{e}$ (IRI), scaled by factors of 0.1-1.0. In determination of the energy losses of electrons resulting from their collisions with neutral particles, use has been made of the generally accepted expressions for the fine structure cooling by $\mathrm{O}$ given by Hoegy (1976) and the revised electron cooling rates by vibrational and rotational excitation of $\mathrm{O}_{2}$ and $\mathrm{N}_{2}$ given by Pavlov (1998 a,c). These revised electron cooling rates by vibrational excitation of $\mathrm{O}_{2}$ and $\mathrm{N}_{2}$ depend on number densities of vibrationally excited $\mathrm{O}_{2}$ and $\mathrm{N}_{2}$, and to calculate $T_{e}$ our model has to solve time-dependent continuity equations for vibrationally excited molecular oxygen and nitrogen, $\mathrm{O}_{2}(\mathrm{v})$ and $\mathrm{N}_{2}(\mathrm{v})$, at the first five vibrational levels $\mathrm{v}=1-$ 5 and the time-dependent energy equations for their vibrational quanta as described by Pavlov (1997, 1998 b). The cooling rate of electrons upon their collisions with ions depends on the ion temperature $T_{i}$, which is practically the same for all sorts of ions in the ionosphere. Therefore, the ion heat balance equation is 
needed to solve simultaneously with Eq. (8) in the ionosphere as (Rees and Rouble, 1975)

$0.5 \frac{\partial}{\partial t} T_{i}=v_{\mathrm{ie}}\left(T_{e}-T_{i}\right)+m_{i}\left(T_{n}-T_{i}\right) \sum_{n} v_{\mathrm{in}}\left(m_{i}+m_{n}\right)^{-1}$

where $m_{i}$ denotes the mass of $\mathrm{O}^{+}$ions, $v_{\text {ie }}$ and $v_{\text {in }}$ are the collision frequencies for momentum transfer between $\mathrm{O}^{+}$ions and electrons and between $\mathrm{O}^{+}$ions and neutrals, $m_{n}$ denotes the mass of the $n$-th neutral species.

At the lower boundary $(120 \mathrm{~km})$ the processes of transfer of thermal energy of electrons and vibrationally excited molecules are neglected. For the upper boundary conditions $(1400 \mathrm{~km})$, the absence of flows of $\mathrm{O}_{2}(\mathrm{v})$ and $\mathrm{N}_{2}(\mathrm{v})$ is assumed. The electron heat flux at the upper boundary is established in the range of $2.5 \cdot 10^{10}$ $1.0 \cdot 10^{11} \mathrm{eV} \mathrm{cm}^{-2} \mathrm{~s}^{-1}$ which is typical for SAR arcs (Rees and Rouble, 1975).

In this work we present the results of the study of the dependence of $T_{e}$ on $N_{e}$ and $\Phi\left(-s_{1}\right)$ at $23.00 \mathrm{LT}$ on 18 December, 1971 in the SAR arc region during the recovery phase of the double geomagnetic storm of 1619 December, 1971 at geographic latitude $42^{\circ}$ and geographic longitude $279.5^{\circ}$ ( $L$ shell value of the geomagnetic field line is 2.8) at moderate solar activity with $F 10.7=135$. Observations of the ion composition and temperature, electron temperature and density height profiles from the altitude of the Isis 2 spacecraft down to the $\mathrm{F}$ region, and the intensity of the $630 \mathrm{~nm}$ oxygen emission in this SAR arc region are presented by Maier et al. (1975) and correctly described by the IZMIRAN model (Pavlov, 1996).

Figure 1 shows the sensitivity of the calculated electron temperatures in the studied SAR arc region to model assumptions at $300 \mathrm{~km}$ altitude (bottom panel), $400 \mathrm{~km}$ altitude (middle panel), and $500 \mathrm{~km}$ altitude (top panel): (1) the model electron density is given as $N_{e}$ (IRI) scaled by factors of $0.1-1.0$, and (2) the electron heat flux at $1400 \mathrm{~km}$ along a geomagnetic field line is given as $1.0 \cdot 10^{11} \mathrm{eV} \mathrm{cm}^{-2} \mathrm{~s}^{-1}$ (solid lines), $5.0 \cdot 10^{10} \mathrm{eV} \mathrm{cm}^{-2} \mathrm{~s}^{-1}$ (dotted lines), and 2.5 . $10^{10} \mathrm{eV} \mathrm{cm}^{-2} \mathrm{~s}^{-1}$ (dashed lines). It is immediately obvious that for the same heat flow, the electron temperature is hotter in the presence of the low electron density in agreement with the conclusions of Kozyra et al. (1990) and Fok et al. (1991a, b). However, changes in the electron density do not significantly effect the electron temperature (in comparison with those obtained by Kozyra et al. (1997) and Fok et al. (1991a, b) resulting from the given heat flux of electrons as demonstrated in Fig. 1. On the other hand, rather extensive experimental data of simultaneous measurements of $N_{e}$ and $T_{e}$ showed that the value of $T_{e}$ independent on $N_{e}$ in the SAR arc region (Kozyra et al., 1997; Fok et al., 1991a, b). Our calculations show that changes in the heat flux of electrons from the plasmasphere due to variations of $Q_{r c}(s)$ in the plasmasphere are largely responsible for variations of electron temperatures above $300 \mathrm{~km}$ altitude. As a result, some enhancement of the energy

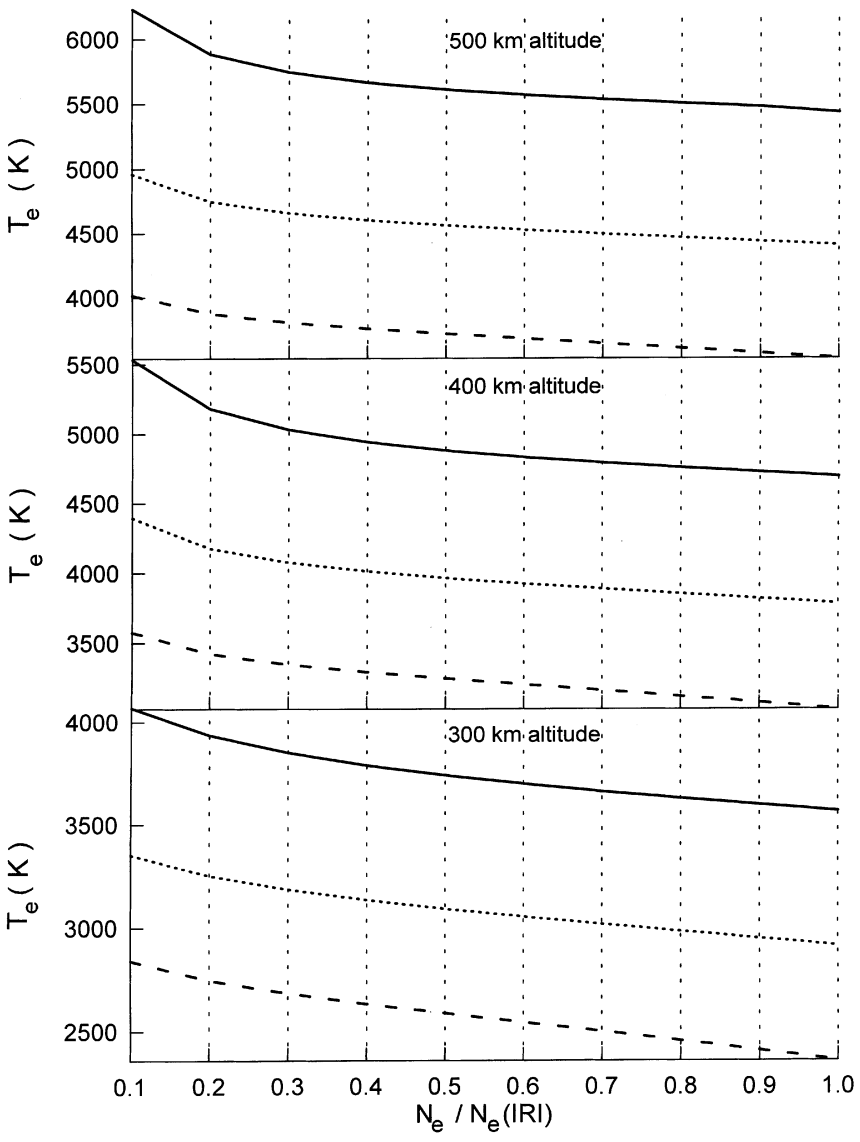

Fig. 1. Variations in the electron temperature at $300 \mathrm{~km}$ (bottom panel), $400 \mathrm{~km}$ (middle panel), and $500 \mathrm{~km}$ (top panel) resulting from reasonable modifications in the electron density from $120 \mathrm{~km}$ to $1400 \mathrm{~km}$ and the heat flux of electrons at $1400 \mathrm{~km}$ given as $1.0 \cdot 10^{11} \mathrm{eV} \mathrm{cm}^{-2} \mathrm{~s}^{-1}$ (solid lines), $5.0 \cdot 10^{10} \mathrm{eV} \mathrm{cm}^{-2} \mathrm{~s}^{-1}$ (dotted lines), and $2.5 \cdot 10^{10} \mathrm{eV} \mathrm{cm}^{-2} \mathrm{~s}^{-1}$ (dashed lines) at $23.00 \mathrm{LT}$ on 18 December, 1971, in the SAR arc region at the geographic latitude $42^{\circ}$ and geographic longitude $279.5^{\circ}$

losses for thermal electrons at solar maximum due to the enhanced ionospheric electron density is compensated by the enhanced $\mathrm{O}^{+}$content of the ring current, so that $T_{e}$ is relatively independent of the solar cycle.

It can be seen from Eq. (9) that the electron heating rate due to ring current depend on the density and temperature of plasmasphere electrons. A characteristic time for electron density variations is about 1-2 days in the plasmasphere at $L=3$ (Krinberg and Tashchilin, 1984). Hence, although $N_{e}$ in the plasmasphere is related to the $\mathrm{F} 2$ region electron density, the characteristic time scale of this relationship is about 1-2 days, and, as a result, the variations of the SAR arc electron temperatures with characteristic times from several minutes to several hours do not connect with the variations of $N_{e}$ in the plasmasphere. The characteristic cooling time of electrons in the plasmasphere is much larger than the characteristic time of $T_{e}$ variations due to thermal conductivity of electrons, and we conclude that the only reason for these electron temperature variations are time variations of $C$ in Eq. (9), i.e., time variations of ring current parameters. The time variations of the SAR arc 
electron temperatures with characteristic time of about a day or a few days are related to time variations of the plasmaspheric electron density (since $Q_{r c}$ is proportional to $N_{e}$ ) and ring current parameters.

Finally, analysis of this section shows that SAR arc intensity time variations with characteristic times from several minutes to several hours are stipulated by time variations in the neutral atmosphere by means of $J$ time variations, the ring current time variations through time variations of $\left\langle f\left(T_{e}\right)\right\rangle$, and the time variations of $\left\langle N_{e}\right\rangle$ in the ionosphere (see Eq. 6).

\section{Results of the statistical study and discussion}

This study uses a catalogue of all SAR arc occurrences, as identified by the Pacific Northwest Laboratory Photometer Network during 1978-1988 compiled by Slater and Kleckner (1989). This catalogue contains dates, times, intensities of $630 \mathrm{~nm}$ emission, positions of SAR arcs in terms of Mcllwain parameter $L$, and the location of photometers. The main criteria used for identification of SAR arcs are an enhancement of $630 \mathrm{~nm}$ emission rates in excess of about $40 \mathrm{R}$ and spectral purity, i.e., the absence of 557.7 and $427.8 \mathrm{~nm}$ emissions.

These data published by Slater and Kleckner (1989) are complemented using values of geomagnetic indices $D s t$ and $K p$ and solar index $F 10.7$. As we have already note in the foregoing, the correlations between emissions at $630 \mathrm{~nm}$ with $D s t$ and $K p$ were found at the early stages of SAR arc investigations (Rees and Akasofu, 1963; Roach and Roach, 1963). This result seems to be quite natural because SAR arcs are associated with geomagnetic storms and $D s t$ is a measure of ring current energy increase as compared with quiet periods and $K p$ estimates the amplitude of magnetic "noise" and can be used as a rough indicator of the geomagnetic activity. It is also known that the ion composition of the ring current depends on $K p$ and $F 10.7$ (Young et al., 1982). On the other hand, parameters of neutral atmosphere also depend on solar and geomagnetic activity.

For each measurement the value of $J$ given by Eq. (7) is calculated. To calculate temperature and densities of neutral components of atmosphere we use the MSIS-86 model with seven 3-h $A p$ indices as input parameters (Hedin, 1987). Then from all SAR arcs observed we select for our analysis the "simplest events" that satisfy the following conditions. First, each SAR arc selected is associated with a geomagnetic storm with well-defined main and recovery phases as seen from time profiles of Dst. Second, if the SAR arc is preceded by two storms, then these storms should not overlap (we reject the data if the time spacing between $D s t$ minima is less than $12 \mathrm{~h}$ ). Third, there are no observed emissions at the main phase of the storm. The grand total of the measurements selected comprises $648 \mathrm{~h}$ of observations. For each measurement we also assign the corresponding value of minimum Dst which is denoted as $D s t_{\min }$ and the time lapse between the onset of the recovery phase and the measurement denoted as $t$. Histograms for $D s t_{\min }$, Dst,
$K p, F 10.7, \log (I)$, and $\log (I / J)$, which are involved in further analysis, are shown in Figs. 2 and 3.

The histogram for $D s t_{\min }$ in Fig. 2a shows that all events fall into at least two classes and the boundary between them is about $-100 \mathrm{nT}$. It is also worth noting that SAR arcs occur most frequently and have the largest intensities during the equinoxes, in winter they are considerably weaker and rarer, and they are only rarely observed in summer (Hoch, 1973; Slater and Smith, 1981). For the events selected these variations are illustrated by Table 1, where we place the total duration of observations $n$ and the mean and maximum intensity for each season, $I_{\text {mean }}$ and $I_{\max }$, respectively, and by Fig. 4 , where $I$ and $I / J$ are plotted against the number of days in the year. The reason for these variations may be due to differences in the high-altitude heat source and to seasonal changes in the atmosphere and ionosphere (Kozyra et al., 1990).

It is easily seen from Figs. 2 and 3 that distributions of the quantities involved are not normal and the data are also subject to outliers. Since we use the methods of classical statistics which hold for normal distributions, in order to obtain reliable values of different statistical parameters we must reject outliers and use some
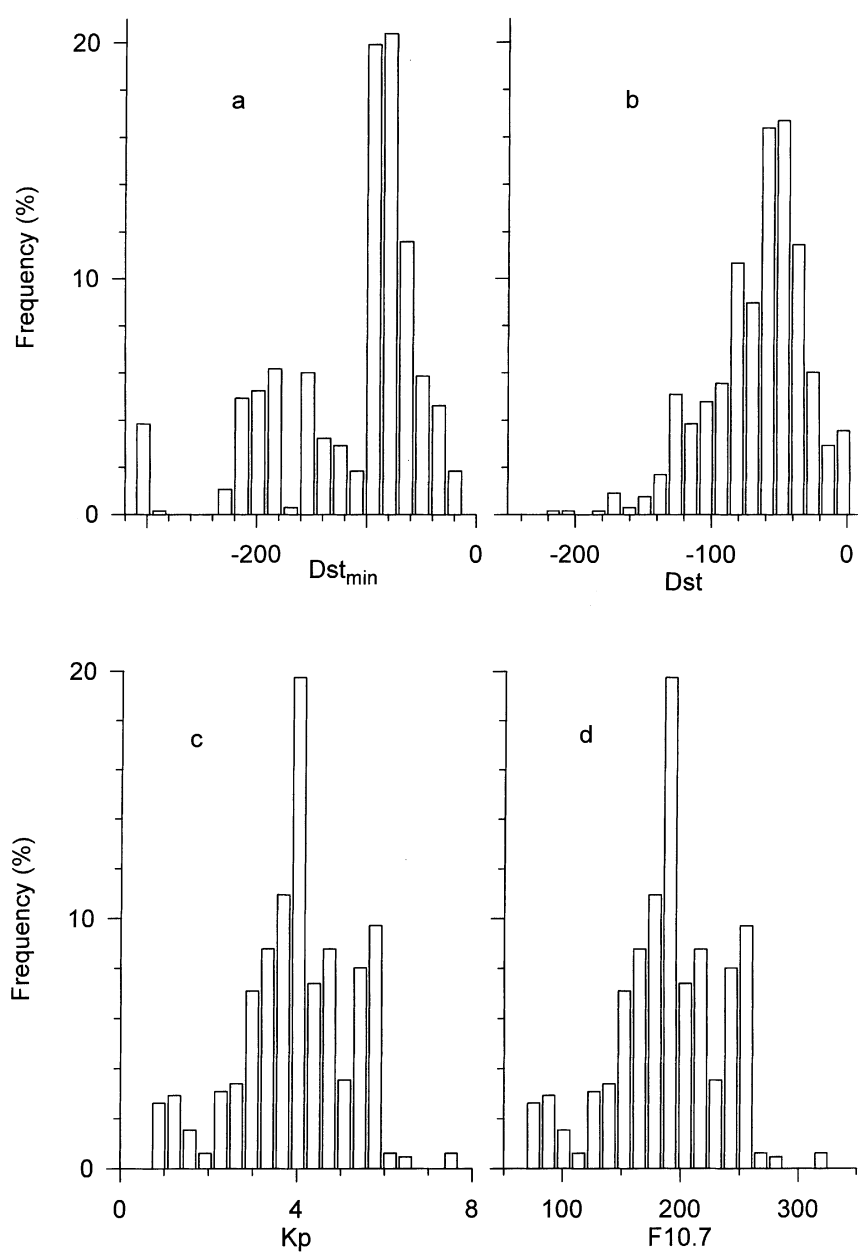

Fig. 2a-d. Histograms for indices a $D s t_{\min }$, b $D s t$, c $K p$, and $\mathbf{d} F 10.7$ characterizing solar and geomagnetic activity during SAR arc events involved in the statistical analysis 

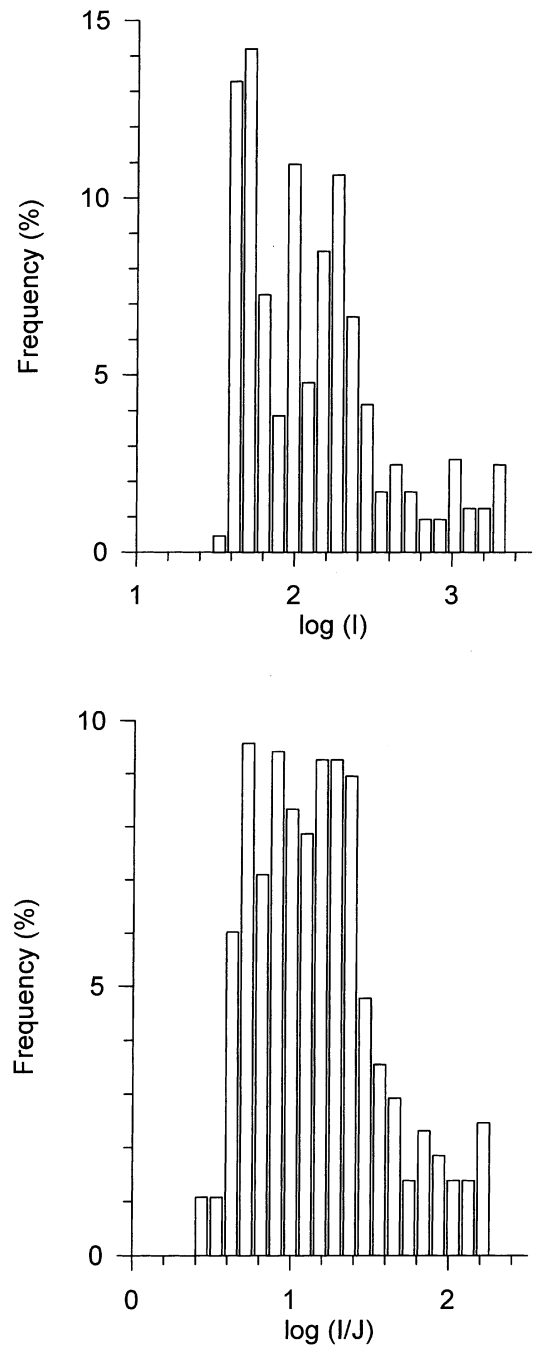

Fig. 3. Histograms for $I 1=\log (I)($ top $)$ and $I 2=\log (I / J)$ (bottom), where $I$ is the SAR arc intensity and $J$ is given by Eq. (7)

procedures that remove deviations from normality at each stage of investigation (see Appendix for details).

At the first stage we must test the hypothesis that SAR arc intensity does depend on the indices chosen. For this purpose we calculate the correlation coefficients $r_{I 1, D s t}, r_{I 1, F 10.7}, r_{I 1, K p}, r_{I 2, D s t}, r_{I 2, F 10.7}$, and $r_{I 2, K p}$. Here and in the following $I 1=\log (I), I 2=\log (I / J)$, and $r_{I 1, D s t}$, for example, is the coefficient of correlation between $I 1^{\lambda 1}$ and $|D s t|^{\lambda D s t}$ where $\lambda 1$ and $\lambda D s t$ are exponents (see Appendix). The absolute value of Dst is taken because Dst is negative in all the cases considered. For brevity, we shall refer, for example, to correlations between $I 1$ and $D s t$ rather than between $I 1^{\lambda 1}$ and

Table 1. Seasonal variations of SAR arc occurence and intensity

\begin{tabular}{lcccc}
\hline & Winter & Spring & Summer & Autumn \\
\hline$n$, hours & 167 & 196 & 45 & 240 \\
$I_{\text {mean }}, R$ & 150 & 288 & 110 & 309 \\
$I_{\text {max }}, R$ & 1000 & 1900 & 500 & 2200 \\
\hline
\end{tabular}

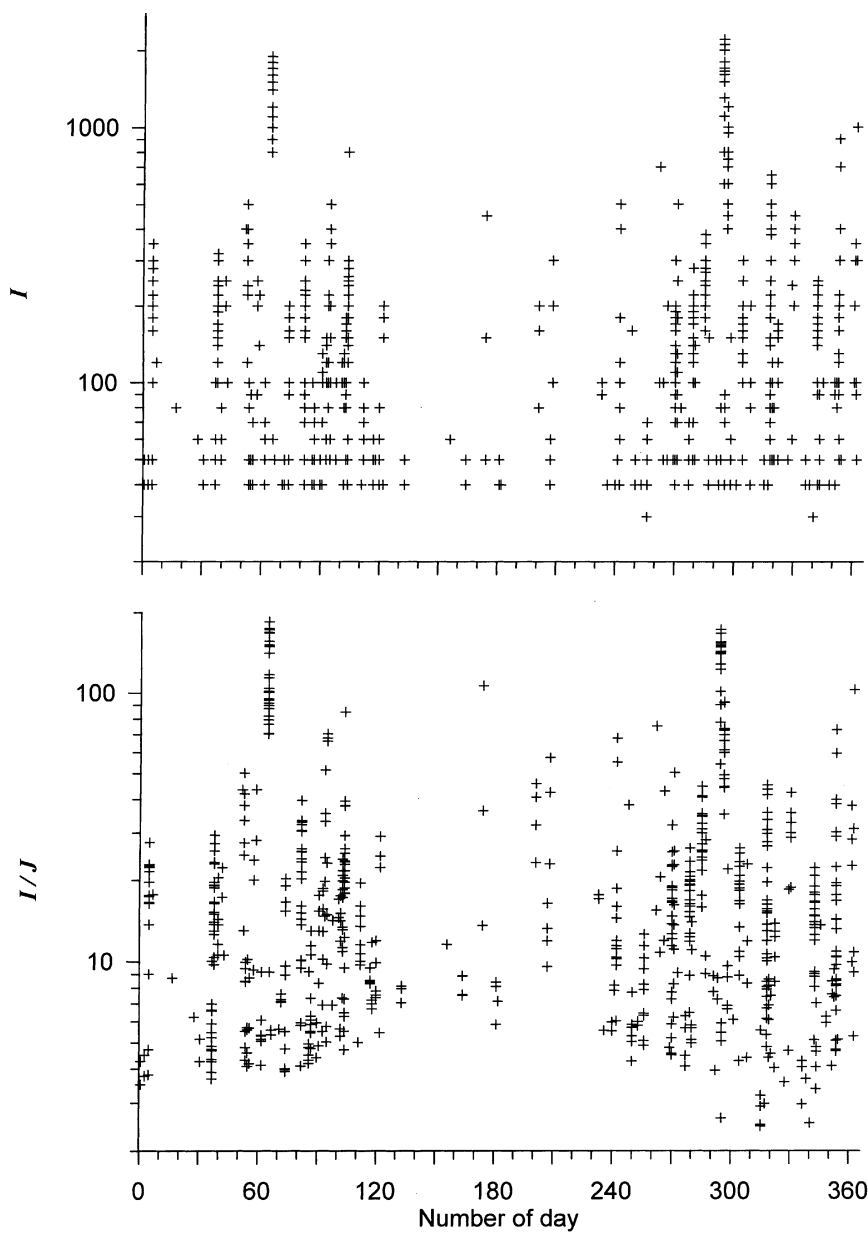

Fig. 4. Dependence of SAR arc intensity $I$ (top) and the ratio $I / J$ (bottom) on the number of day in the year. The value of $J$ is given by Eq. (7)

$|D s t|^{\lambda D s t}$. The values of correlation coefficients are summarized in Table 2 . We see that both $I 1$ and $I 2$ exhibits a striking dependence on $D s t$ and are also well correlated with $K p$. There is the large correlation between $I 1$ and $F 10.7$, but there is no significant correlation between $I 2$ and $F 10.7$. Since the dependences of both $I 1$ and $I 2$ on several indices are statistically significant, we use the technique of multiple regression analysis given by, for example, Aivazyan et al. (1985). The calculated partial correlation coefficients $r_{I 1, D s t}, r_{I 1, F 10.7}, r_{I 1, K p}, r_{I 2, D s t}, r_{I 2, F 10.7}, r_{I 2, K p}$, and multiple correlation coefficient squared $R^{2}$ are shown in Table 3 . The notations for partial correlation coefficients are the same as for zero-order correlation coefficients. This will not lead to a confusion because in the following we shall be concerned only about the partial correlation

Table 2. Correlation coefficients calculated for whole set of data

\begin{tabular}{cccc}
\hline & $|D s t|$ & $F 10.7$ & $K p$ \\
\hline$I 1$ & $0.49 \pm 0.05$ & $0.21 \pm 0.06$ & $0.13 \pm 0.06$ \\
$I 2$ & $0.52 \pm 0.05$ & $0.06 \pm 0.07$ & $0.17 \pm 0.06$ \\
\hline
\end{tabular}


Table 3. Partial correlation coefficients calculated for whole set of data

\begin{tabular}{lcrcl}
\hline & $|D s t|$ & \multicolumn{1}{c}{$F 10.7$} & $K p$ & $R^{2}$ \\
\hline$I 1$ & $0.46 \pm 0.05$ & $0.17 \pm 0.06$ & $-0.03^{\mathrm{a}} \pm 0.07$ & 0.27 \\
$I 2$ & $0.50 \pm 0.05$ & $-0.01^{\mathrm{a}} \pm 0.07$ & $-0.02^{\mathrm{a}} \pm 0.07$ & 0.27 \\
\hline
\end{tabular}

${ }^{a}$ Statistically insignificant values at the 0.90 confidence level

coefficients. From Table 3 we observe that both $I 1$ and $I 2$ are strongly dependent on Dst, and there are no dependences of $I 1$ and $I 2$ on $K p$. Large correlations with $F 10.7$ are observed only for $I 1$, thereby suggesting that the neutral atmosphere is responsible for them.

The object of the next step of our analysis is to obtain preliminary information as to whether there are any dependences of the correlation coefficients on season, intensity of storms, and the time offset, $t$, between the time of SAR arc intensity measurements and the onset of the geomagnetic storm recovery phase. First, we select two sets of data which are obtained in winter and in spring and autumn, respectively. The corresponding partial correlation coefficients are shown in Table 4 . The data obtained in summer are not considered because they are few in number. Second, from all data we choose that corresponding to strong $\left(D s t_{\min } \leq-100 \mathrm{nT}\right)$ and weak $\left(D s t_{\min }>-100 \mathrm{nT}\right)$ storms and again calculate partial correlation coefficients (see Table 5). We can conclude that there is a significant difference between winter and spring/autumn data, as well as between the data corresponding to strong and weak storms.

At third, we calculate the correlation coefficients for data sets such that the time offset from the onset of the recovery phase lies within the time range $T-2 \mathrm{~h} \leq t \leq T+2 \mathrm{~h}$, where $T$ is sequentially increased with an increment of $1 \mathrm{~h}$. The width of the time window which is equal to $5 \mathrm{~h}$, is a compromise between the time resolution and the statistical reliability of the results. The dependence of the number of data points in the window on $T$ is shown in Fig. 5. Figures 6 and 7 shows that all correlation coefficients both for $I 1$ and $I 2$ do depend on $T$.

The preceding causes the question: what kind of data sorting must we choose to obtain the "simplest" SAR arc events which are characterized by large values of multiple correlation coefficients? In Figs. 6 and 7, we observe a wide peak of the multiple correlation coefficient squared $R^{2}$ with the centre about $12 \mathrm{~h}$, and the maximum value of about 0.40 . This is the largest value from all obtained above. It should be noted that all correlation coefficients are approximately constant within the time interval $8 \mathrm{~h} \leq T \leq 14 \mathrm{~h}$. As the window moves from the centre of the peak, the multiple correlation coefficient decreases to rather small values. Then, we find that $R^{2}$ is a maximum when

$8 \mathrm{~h} \leq t \leq 16 \mathrm{~h}$

and $R^{2}$ decreases when the width of the window given by Eq. (13) is increased by moving any of its boundaries or both of them. We suggest that this result illustrates the fact that the processes involved in the SAR arc formation are the "simplest" in the time interval of Eq. (13) and much more complex both at the beginning and at the end of the recovery phase. It is worth also noting that the fractions of spring/autumn and winter data, as well as fractions of data obtained during strong and weak storms in the interval Eq. (13) are approximately the same as for the whole data set (see Table 6, where in parentheses there are also shown the duration of corresponding measurements in hours). It is this fact that leads us to the conclusion that to obtain large correlations we must sort the data by the time offset from the onset of the recovery phase rather than by season or storm intensity. The reliability of this result is strengthened by the fact that the peak of $n$ distribution is also within the interval of Eq. (13) (see Fig. 5) and, as a result, there are about a half of data points satisfy the condition of Eq. (13) (namely, 310 hours of observations).

As stated SAR arc events are the "simplest" when the time lapse between the intensity measurement and the onset of the storm is within the interval of Eq. (13) and, consequently, the "complexity" of SAR arcs increases as we move to the main phase or in the opposite direction. Physical reasons for this complexity increase may be entirely different in these two cases. We can suppose that for larger $t$ than given by Eq. (13) we deal with more weak SAR arcs, for which intensity is influenced by a larger number of processes in the atmosphere and ionosphere. In contrast, although SAR arcs are more intense close to peaks of Dst indices and it seems probable that its intensities depend mostly on parameters of ring current, the dynamics of the ring current here is much more complex than in the middle of the recovery phase.

At the next step of our analysis we select data for which the time lapse between the measurement and the onset of the recovery phase is within the interval of Eq. (13). The results of calculations of partial correlation coefficients are summarized in Table 7. Table 7 shows that the absolute values of these coefficients are larger
Table 4. Seasonal variations of partial correlation coefficients

\begin{tabular}{lcrrrr}
\hline & & \multicolumn{1}{c}{$\mid$ Dst $\mid$} & \multicolumn{1}{c}{$F 10.7$} & \multicolumn{1}{c}{$K p$} & $R^{2}$ \\
\hline Winter & $I 1$ & $0.22 \pm 0.12$ & $0.06^{\mathrm{a}} \pm 0.13$ & $0.19 \pm 0.13$ & 0.12 \\
& $I 2$ & $0.20 \pm 0.13$ & $-0.07^{\mathrm{a}} \pm 0.13$ & $0.21 \pm 0.12$ & 0.13 \\
Spring- & $I 1$ & $0.52 \pm 0.06$ & $0.21 \pm 0.08$ & $-0.09 \pm 0.08$ & 0.34 \\
Autumn & $I 2$ & $0.55 \pm 0.06$ & $0.00^{\mathrm{a}} \pm 0.08$ & $-0.06 \pm 0.08$ & 0.33 \\
\hline
\end{tabular}

${ }^{a}$ Statistically insignificant values at the 0.90 confidence level 
Table 5. Dependence of partial correlation coefficients on the storm intensity

\begin{tabular}{lcrrrl}
\hline & & $|D s t|$ & \multicolumn{1}{c}{$F 10.7$} & \multicolumn{1}{c}{$K p$} & $R^{2}$ \\
\hline Weak & $I 1$ & $0.28 \pm 0.08$ & $0.12 \pm 0.08$ & $0.03^{\mathrm{a}} \pm 0.08$ & 0.11 \\
Storms & $I 2$ & $0.27 \pm 0.08$ & $-0.11 \pm 0.08$ & $0.02^{\mathrm{a}} \pm 0.08$ & 0.10 \\
Strong & $I 1$ & $0.31 \pm 0.10$ & $0.33 \pm 0.10$ & $-0.27 \pm 0.10$ & 0.25 \\
Storms & $I 2$ & $0.34 \pm 0.10$ & $0.28 \pm 0.10$ & $-0.23 \pm 0.10$ & 0.23 \\
\hline
\end{tabular}

${ }^{\text {a }}$ Statistically insignificant values at the 0.90 confidence level than those obtained with data for all $t$ (see for comparison Table 3), but the relative importance of indices seems to be approximately the same (the only exception is probably the more significant correlations between $I 2$ and $F 10.7$ under the condition of Eq. (13).

We next consider a question of whether the difference between strong and weak storms still remains significant under the condition of Eq. (13). The results of calculations are shown in Table 8 and can be compared with the results in Table 5. As we have already seen, the absolute values of correlation coefficients for strong storms are larger than those for weak storms. Therefore, the weaker the storms, the more "complex" are SAR arcs (which are characterized by smaller values of multiple correlation coefficients) associated with these storms. The values of $I 1$ and $I 2$ exhibit the largest correlations with $D s t$ for all classes of storms. However, the relative roles of the $F 10.7$ and $K p$ are significantly different for strong and weak storms. If strong storms are considered, then we observe that the correlations of $I 2$ with $D s t$ and $F 10.7$ are approximately equal and there is also large anticorrelations between $I 2$ and $K p$, which, however, are significantly smaller in magnitude. When the storms are weak, the leading role of Dst is more pronounced, considerably smaller correlations between

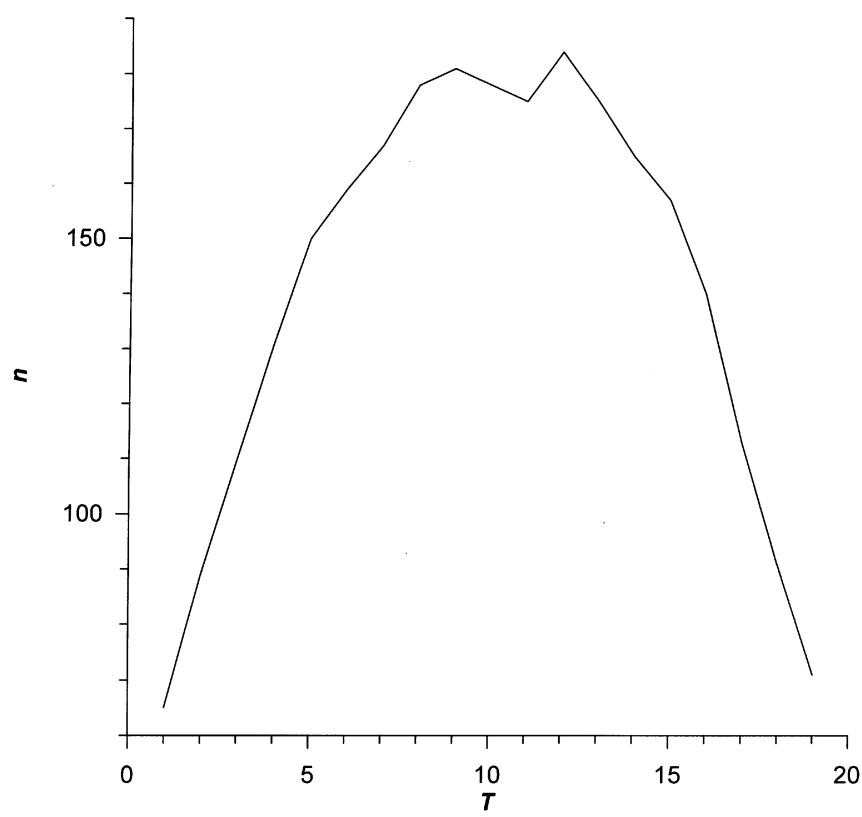

Fig. 5. Dependence of the number $n$ of data points located within the time window $T-2 \mathrm{~h} \leq t \leq T+2 \mathrm{~h}$, on the position of this window. The value of $t$ is the time lapse between intensity measurement and the onset of the storm
$I 2$ and $K p$ are observed, and dependence of $I 2$ on $F 10.7$ is statistically insignificant.

Finally, we can conclude that dependences of $I 1$ and $I 2$ on Dst, $F 10.7$ and $K p$ are significantly different for SAR arcs associated with strong and weak storms. This fact does not imply that physical mechanisms of SAR arc formation are entirely different for the two cases. It looks as if the physical mechanisms are the same, but the relative importance of different processes involved varies. For strong storms the ring current intensity, which correlates with Dst, and composition of ring current exhibit a dominant role. Observed large correlations of $I 1$ and $I 2$ with $F 10.7$ can be attributed to the increase of $\mathrm{O}^{+}$content thereby confirming the mechanism of plasmasphere electron energization suggested by Kozyra et al. (1987). The nature of less pronounced but significant anticorrelations of $I 2$ with $K p$ for strong

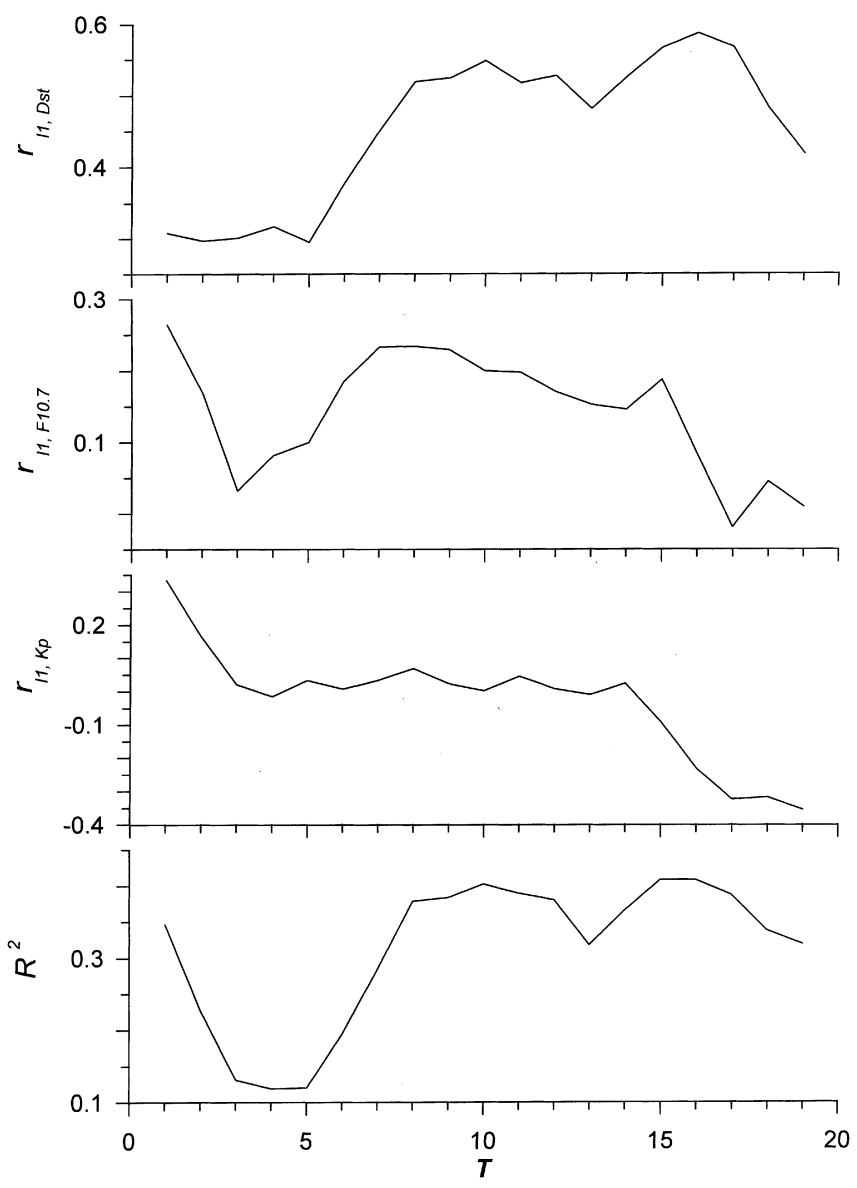

Fig. 6. Dependence of the partial correlation coefficients, $r_{I 1, D s t}, r_{I 1, F 10.7}, r_{I 1, K p}$, and the multiple correlation coefficient squared $R^{2}$ on the position of the window determined by $T$ 


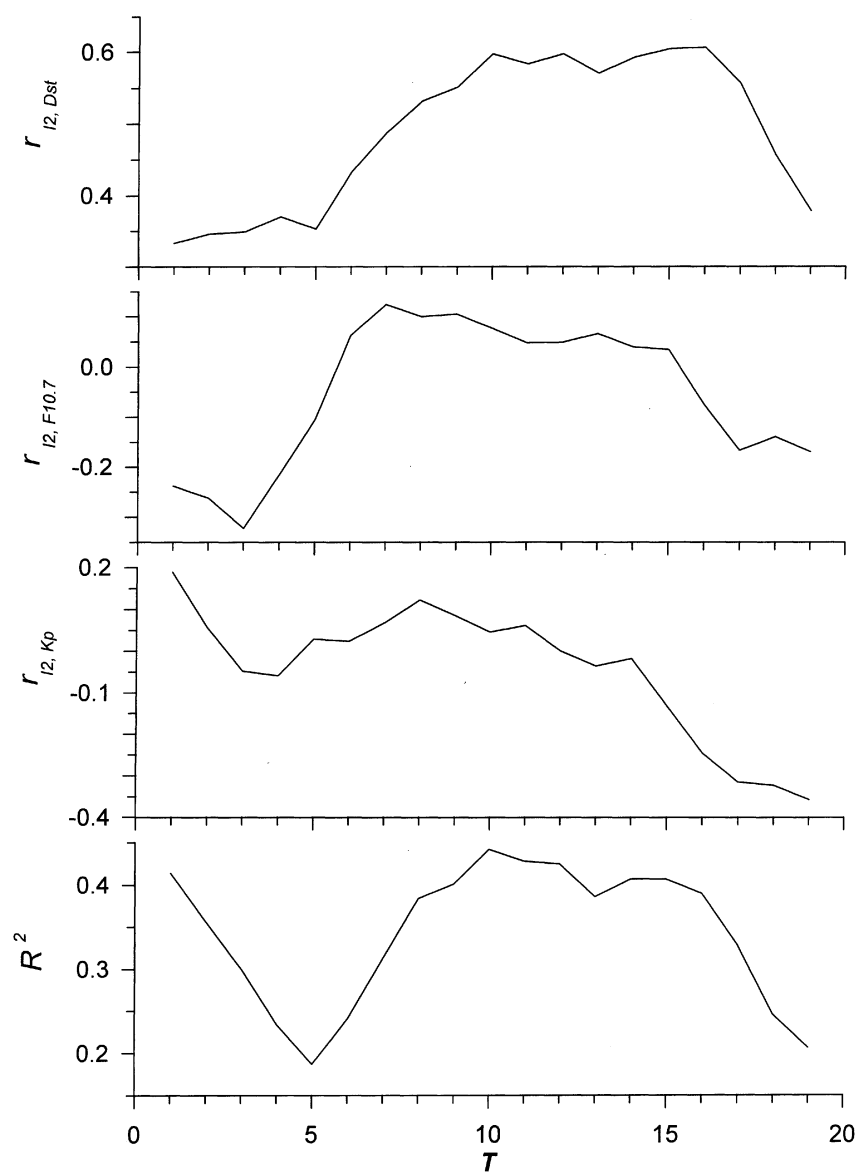

Fig. 7. Dependence of the partial correlation coefficients, $r_{I 2, D s t}, r_{I 2, F 10.7}, r_{I 2, K p}$, and the multiple correlation coefficient squared $R^{2}$ on the position of the window determined by $T$

storms is unclear now, and we intend to solve this problem in our future studies. Proceeding to less intense storms, we can conclude that the role of ring current parameters becomes less pronounced as compared with the role of the neutral atmosphere and electron density (the values of $J$ and $\left\langle N_{e}\right\rangle$ in Eq. 6). Consequently, the number of physical phenomena which determine the SAR arc intensity are increased and, as a result, the multiple correlation coefficient decreases.

It is notable that for weak storms the correlations between $I 2$ and $F 10.7$ are insignificant, while for strong storms we observe large positive correlations. One possible explanation of this difference is as follows. It can be suggested that the sources of ring current ions for these two cases are different. During large storms, the ionosphere is the main source of the energetic ions $\mathrm{O}^{+}$of the ring current, therefore the electron heat flux, which is proportional to the $\mathrm{O}^{+}$content of the ring current, increases with the increase of the ionospheric density. The electron cooling also increases as the electron density increases. As a result, sources and sinks of energy vary in phase and the electron temperature remains relatively constant. Positive correlations between $I 2$ and $F 10.7$ are observed in this case due to correlations between $N_{e}$ and $F 10.7$. During small storms, the majority of the ring current plasma comes from the solar wind or some other source not directly varying with the ionospheric density. In this case the electron heat flux does not vary in phase with the electron cooling rate because they are not both controlled by the electron density in the ionosphere. Because of this, there develops an inverse relationship between $T_{e}$ and $N_{e}$ as follows. At given Dst, one might expect the same electron heat flux regardless of the F10.7, but electron density varies in phase with $F 10.7$. For high electron densities, the electron temperature that can be supported by a fixed flux is lower than in the case of low densities. As a result, the product $\left\langle N_{e}\right\rangle\left\langle f\left(T_{e}\right)\right\rangle$ remains fairly constant and we do not observe significant correlation between $I 2$ and $F 10.7$.

It is known that geomagnetic activity as a whole, as well as the occurrence of intense storms, has a seasonal variability with maxima at the equinoxes (Russel and McPherron, 1973; Gonzalez and Tsurutani, 1992). It seems probable this variability accounts for the seasonal variations of correlation coefficients (compare Tables 4 and 5). Unfortunately, we cannot obtain more definite answer on this question because the data available are not so numerous.

\section{Conclusions}

The primary object of the present work is to find the statistical relationships between SAR arc intensities and solar and geomagnetic activity measured in terms of indices Dst, F10.7, and $K p$, using the method of multiple regression analysis and experimental data acquired by the Pacific Northwest Laboratory Photometer Network during 1978-1988 (Slater and Kleckner, 1989). We find significant correlations between intensity and all of the indices involved. For the first time it is shown that all correlation coefficients depend on the time offset, $t$, from the onset of the recovery phase, the largest correlations are observed when $8 \mathrm{~h} \leq t \leq 16 \mathrm{~h}$. If we consider only the data satisfying this condition, we observe that there are significant differences between correlation coefficients calculated for SAR arcs associated with strong and weak storms with $D s t_{\min } \leq-100 \mathrm{nT}$ and $D s t_{\min }>-100 \mathrm{nT}$, respectively. The considerably larger value of multiple correlation coefficient for strong
Table 6. The fraction of data obtained in winter and spring/ autumn and during strong and weak storms
Fraction (duration, hours)

Total Time interval of Eq. (13)

$0.26 / 0.68(162 / 426)$

$0.64 / 0.36(406 / 225)$
$0.19 / 0.74(60 / 228)$

$0.61 / 0.39(190 / 120)$ 
Table 7. Partial correlation coefficients calculated for set of data satisfying the condition of Eq. (13)

\begin{tabular}{ccccc}
\hline & $|D s t|$ & $F 10.7$ & $K p$ & $R^{2}$ \\
\hline$I 1$ & $0.56 \pm 0.06$ & $0.21 \pm 0.09$ & $-0.01^{\mathrm{a}} \pm 0.09$ & 0.41 \\
$I 2$ & $0.59 \pm 0.06$ & $0.09 \pm 0.09$ & $0.00^{\mathrm{a}} \pm 0.09$ & 0.43 \\
\hline
\end{tabular}

${ }^{a}$ Statistically insignificant values at the 0.90 confidence level

storms than for weak ones indicates that the number of physical phenomena which determine the SAR arc intensity is increased with the decrease of storm intensity.

We have also studied the electron energy balance equation in the ionosphere and plasmasphere along a magnetic field line associated with a SAR arc region. Our calculations show that the electron temperature in the SAR arc region does not strongly depend on the electron density in agreement with simultaneous measurements of $N_{e}$ and $T_{e}$ given by Fok et al. (1991a, b) and Kozyra et al. (1997), and $T_{e}$ is strongly coupled to the additional heating of the electron gas due to interaction of the ring current ions and plasmaspheric electrons. As a result, variations of $T_{e}$ in the SAR arc region with characteristic time scales from several minutes to several hours are stipulated by time variations of ring current parameters. The SAR arc intensity time variations with characteristic time from several minutes to several hours are stipulated by time variations in the neutral atmosphere by means of $J$ time variations, the ring current time variations through time variations of $\left\langle f\left(T_{e}\right)\right\rangle$, and the time variations of $\left\langle N_{e}\right\rangle$ in the ionosphere (see Eq. 6).

Acknowledgements. The research described in this publication was supported by grant 96-05-64031 from the Russian Foundation of the Fundamental Researches. We would like to thank anonymous referees for critical reading of the manuscript as reviewers and for helpful comments.

Topical Editor D. Alcaydé thanks M. C. Fok and J. Kozyra for their help in evaluating this paper.

\section{Appendix. Statistical methods used in data processing}

\section{Rejecting outliers and removing deviations from normality}

Since we use methods of classical statistics which hold for normal distributions, in order to obtain reliable values of different statistical parameters we must reject outliers and use some procedures that remove deviations from normality at each stage of investigation.
Rejecting outliers is the first step of data processing. This procedure begins with finding the point $x_{i}$ (here $x$ stands for Dst, F10.7, Kp, I1, or I2) which is farthest from the mean value $\bar{x}$. Then, if

$\left|x_{i}-\bar{x}\right| / \bar{S}>t_{(p, n-2)}\left(\frac{n-1}{n-2+t_{(p, n-2)}^{2}}\right)^{1 / 2}$,

where $n$ is the number of data points, $\bar{S}$ is a sample standard deviation normalized by $(n-1), t_{(p, n)}$ is $p$ quantile of Student's distribution function with $n$ degrees of freedom, this point must be rejected. We choose $p=0.999$ as recommended by Lvovsky (1982). This procedure continues until there is no outlier.

Usually the distributions we deal with in this study are far from being normal. A number of different procedures have been proposed in the literature for removing deviations from normality (see, for example, Aivazyan et al., 1983). We choose one of the simplest one-parameter change of variables

$y=x^{\lambda}$.

For each kind of data $x$ we choose $\lambda$ such that the absolute value of skewness

$g_{1}=m_{3} / m_{2}{ }^{3 / 2}$

is minimum. Here $m_{n}$ is $n$-th sample moment about the mean. Then, to test the hypothesis that the distribution of $y$ is normal, we calculate also the excess

$g_{2}=m_{4} / m_{2}^{2}-3$

and mean square deviations for $g_{1}$ and $g_{2}$ given by

$\begin{aligned} S_{g 1} & =\sqrt{\frac{6 n(n-1)}{(n-2)(n+1)(n+3)}}, \\ S_{g 2} & =\sqrt{\frac{24 n(n-1)^{2}}{(n-3)(n-2)(n+3)(n+5)}} .\end{aligned}$

We consider the deviations from normality to be statistically negligible if the following inequalities hold (Lvovsky, 1982):

$\left|G_{1}\right|<3 S_{g 1}$ and $\left|G_{2}\right|<5 S_{g 2}$.

Testing the statistical significance and calculating the confidence intervals for correlation coefficients

If a correlation coefficient $r$ is found from $n$ sets of values, its difference from zero is considered to be statistically significant if
Table 8. Dependence of partial correlation coefficients on the storm intensity for the set of data satisfying the condition of Eq. (13)

\begin{tabular}{|c|c|c|c|c|c|}
\hline & & $|D s t|$ & $F 10.7$ & $K p$ & $R^{2}$ \\
\hline Weak & $I 1$ & $0.25 \pm 0.11$ & $0.14 \pm 0.12$ & $0.18 \pm 0.12$ & 0.18 \\
\hline Storms & $I 2$ & $0.24 \pm 0.11$ & $-0.02^{\mathrm{a}} \pm 0.12$ & $0.15 \pm 0.12$ & 0.13 \\
\hline Strong & $I 1$ & $0.47 \pm 0.12$ & $0.35 \pm 0.13$ & $-0.33 \pm 0.14$ & 0.46 \\
\hline Storms & $I 2$ & $0.43 \pm 0.13$ & $0.41 \pm 0.13$ & $-0.31 \pm 0.14$ & 0.46 \\
\hline
\end{tabular}

${ }^{a}$ Statistically insignificant values at the 0.90 confidence level 
$|r|\left[(n-2)\left(1-r^{2}\right)^{-1}\right]^{1 / 2}>t_{0.90}(n-2)$,

where $t_{0.90}(n-2)$ is 0.90 -quantile of Student's distribution function with $(n-2)$ degrees of freedom, for large $n$ we can use a limiting value $t_{0.90}(\infty) \approx 1.282$ (see, for example, Aivazyan et al., 1985). If the inequality (A2) is violated, we say that there is no statistical relationship between the values considered.

The boundaries of the confidence interval for correlation coefficient $r$ are given by

$r \pm u_{0.95}\left(1-r^{2}\right) n^{-1 / 2}$

where $u_{0.95} \approx 1.6449$ is 0.95 -quantile of the normal distribution function with zero mean and unit variance. Eq. (A8) is valid if $n$ is large and $r$ is not in the vicinity of \pm 1 (Aivazyan et al., 1985).

For partial correlation coefficients used in our study we can use Eqs. (A7) and (A8), where $n$ is replaced by $n-2$.

Our calculations show that the absolute values of correlation coefficients is not sensitive to variations of $\lambda^{6} \mathrm{~s}$ in Eq. (A2). This is the reason why we do not include $\lambda$ 's in Tables $2-5,7$, and 8 . On the other hand, the sign of correlation coefficient depend the signs of $\lambda$ 's. The signs of correlation coefficients in Tables $2-5,7$, and 8 are the same as for coefficients calculated without transformation of variables, that is, if $r_{y, x}>0$, then there is a tendency to observe larger values of $y$ as $x$ is increased.

\section{References}

Aivazyan, S. A., I. S. Yenyukov, and L. D. Meshalkin, Applied Statistics. Bases of modelling and initial data processing (in Russian), Finansy i statistika, Moscow, 1983.

Aivazyan, S. A., I. S. Yenyukov, and L. D. Meshalkin, Applied Statistics. Study of relationships (in Russian), Finansy i statistika, Moscow, 1985.

Bhatia, A. K., and S. O. Kastner, The neutral oxygen spectrum. 1. Collisionally excited level populations and line intensities under optically thin conditions, Astrophys. J. Suppl. Ser., 96, 325, 1995.

Bilitza, D., Progress report on IRI status, Adv. Space Res., 10, (11)3, 1990 .

Cole, K. D., Stable auroral red arcs, sinks for energy of Dst main phase, J. Geophys. Res., 70, 1689, 1965.

Cornwall, J. M., F. V. Coroniti, and R. M. Thorne, Unified theory of sar-arc formation at the plasmapause, J. Geophys. Res., 76, 4428, 1971.

Doering, J. P., Absolute differential and integral electron excitation cross-sections for atomic oxygen. 9. Improved cross sections for the ${ }^{3} \mathrm{P} \rightarrow{ }^{1} \mathrm{D}$ transition from 4.0 to $30 \mathrm{eV}$, J. Geophys. Res., 97, 19531, 1992.

Erlandson, R. E., T. L. Aggson, W. R. Hogey, and J. A. Slavin, Simultaneous observations of subauroral electron temperature enhancements and electromagnetic ion cyclotron waves, Geophys. Res. Lett., 20, 1723, 1993.

Fok, M. -C., J. U. Kozyra, M. F. Warren, and L. H. Brace, Seasonal variations in the subauroral electron temperature enhancements, J. Geophys. Res., 96, 9773, 1991a.

Fok, M. -C., J. U. Kozyra, and L. H. Brace, Solar cycle variations in the subauroral electron temperature enhancement: comparison of AE-C and DE 2 satellite observations, J. Geophys. Res., 96, 1861, 1991b.
Gonzalez, W. D., and B. T. Tsurutani, Terrestrial response to erruptive solar flares: geomagnetic storms, in Eruptive Solar Flares, Eds. Z. Svestka, B. V. Jackson, and M. E. Machado, Springer-Verlag, New York, Berlin, Heidelberg, P. 277, 1992.

Hedin, A. E., MSIS-86 thermospheric model, J. Geophys. Res., 92, 4649, 1987.

Hoch R. J. Stable auroral red arcs, Rev. Geophys. Space Phys., 11, 935, 1993.

Hoegy, W. R., New fine structure cooling rate, Geophys. Res. Lett., 3, 541, 1976.

Khazanov, G. V., A. F. Nagy, T. I. Gombosi, M. A. Koen, S. J. Cariglia, Analytic description of the electron temperature behavior in the upper ionosphere and plasmasphere, Geophys. Res. Lett., 19, 1915, 1992.

Krinberg, I. A., and A. V. Tashchilin, Ionosphere and plasmasphere (in Russian), Nauka, Moscow, 1984.

Kozyra, J. U., and A. F. Nagy, Ring current decay-coupling of ring current energy into the thermosphere/ionosphere system, $J$. Geomagn. Geoelectr., 43, 285, 1991.

Kozyra, J. U., E. G. Shelley, R. H. Comfort, L. H. Brace, T. E. Gravens, and A. F. Nagy, The role of ring current $\mathrm{O}^{+}$in the formation of stable auroral red arcs, J. Geophys. Res., 92, 7487, 1987.

Kozyra, J. U., C. E. Valladares, H. C. Carlson, M. J. Buonsanto, and D. W. Slater, A theoretical study of the seasonal and solar cycle variations of stable auroral red arcs, J. Geophys. Res., 95, $12219,1990$.

Kozyra, J. U., A. F. Nagy, and D. W. Slater, High-altitude energy source(s) for stable auroral red arcs, Rev. Geophys., 35, 155, 1997.

Lvovski, E. N., Statistical methods for obtaining empirical formulas (in Russian), Vysshaya shkola, Moscow, 1982.

Maier, E. J., S. Chandra, L. Brace, J. H. Hoffman, G. G. Shepherd, and $\mathbf{J}$. H. Whitteker, The SAR arc event observed during the December 1971 magnetic storm, J. Geophys. Res., 80, 4591, 1975.

Pavlov, A. V., Airglow of the upper atmosphere at $630 \mathrm{~nm}$ by rocket data from "Vertical 6 and 7" (in Russian), Geomagn. Aeron., 30, 261, 1990.

Pavlov, A. V., Mechanisms of the electron density depletion in the SAR arc region, Ann. Geophysicae, 14, 211, 1996.

Pavlov, A. V., Subauroral red arcs as a conjugate phenomenon: comparison of OV1-10 satellite data with numerical calculations, Ann. Geophysicae, 15, 984, 1997.

Pavlov, A. V., New electron energy transfer rates for vibrational excitation of $\mathrm{N}_{2}$, Ann. Geophysicae, 16, 176, 1998a.

Pavlov, A. V., The role of vibrationally excited oxygen and nitrogen in the ionosphere during the undisturbed and geomagnetic storm period of 6-12 April 1990, Ann. Geophysicae, 16, 589, 1998b.

Pavlov, A. V., New electron energy transfer and cooling rates by excitation of $\mathrm{O}_{2}$, Ann. Geophysicae, 16, 1007, 1998c.

Rees, M. H., and S. I. Akasofu, On the association between subvisual red arcs and the Dst $(H)$ decrease, Planet. Space Sci., 11, 105, 1963.

Rees, M. H., and R. G. Roble, Observations and theory of the formation of stable auroral red arcs, Rev. Geophys. Space Phys., 13, 201, 1975.

Roach, F. E., and J. R. Roach, Stable $6300 \AA ̊$ auroral arcs in midlatitudes, Planet. Space Sci., 11, 523, 1963.

Russel, C. T., and R. L. McPherron, Semiannual variation of geomagnetic activity, J. Geophys. Res., 78, 92, 1973.

Slater, D. W., and L. L. Smith, Modulation of stable auroral red (SAR) arc occurrence rates, J. Geophys. Res., 86, 3669,1981.

Slater, D. W., and E. W. Kleckner, Stable auroral red arc occurrences detected by the Pacific Northwest Laboratory Photometer Network: a decade of observations, 1978-1988. Rep. PNL-7184. Pacific Northwest Laboratory, Richland, Wash., 1989.

Sobral, J. H. A., H. Takahashi, M. A. Abdu, P. Muralikrishna, Y. Sahai, C. J. Zamlutti, E. R. de Paula, and P. P. Batista, 
Determination of the quenching rate of the $\mathrm{O}\left({ }^{1} \mathrm{D}\right)$ by $\mathrm{O}\left({ }^{3} \mathrm{P}\right)$ from rocket-borne optical $(630 \mathrm{~nm})$ and electron density data, $J$. Geophys. Res., 98, 7791, 1993.

Spitzer, J., Jr., Physics of fully ionized gases, Interscience Publishers, New York-London, 1962.

Streit, G. E., C. J. Howard, A. L. Schmeltekopf, J. A. Davidson, and H. I. Schiff, Temperature dependence of $\mathrm{O}\left({ }^{1} \mathrm{D}\right)$ rate constants for reactions with $\mathrm{O}_{2}, \mathrm{~N}_{2}, \mathrm{CO}_{2}, \mathrm{O}_{3}$, and $\mathrm{H}_{2} \mathrm{O}$, J. Chem. Phys., 65, 4761, 1976.
Thorne, R. M., and R. B. Horne, The contribution of ion-cyclotron waves to electron heating and SAR-arc excitation near the storm-time plasmapause, Geophys. Res. Lett., 19, 417, 1992.

Thorne, R. M., and R. B. Horne, Modulation of electromagnetic ion cyclotron instability due to interaction with ring current $\mathrm{O}^{+}$ during magnetic storms, J. Geophys. Res., 102, 14155, 1997.

Young, D. T., H. Balsiger, and J. Geiss, Correlations of magnetospheric ion composition with geomagnetic and solar activity, J. Geophys. Res., 87, 9077, 1982. 